Review Article

\title{
Crustal Deformation Studies using Synthetic Aperture Interferometry
}

\author{
K M SREEJITH, RITESH AGRAWAL and A S RAJAWAT* \\ Space Applications Center, Indian Space Research Organization (ISRO), Ahmedabad 380 015, India
}

(Received on 20 May 2016; Accepted on 27 June 2016)

\begin{abstract}
Satellite based Synthetic Aperture Radar interferometry (InSAR) is a well known remote sensing technique to generate digital elevation models of meter-scale accuracy. The technique also enables to measure ground deformation with subcentimeter level accuracy at a spatial resolution of few meters covering on large areas. In this article we review recent studies from India on crustal deformation related to earthquakes using InSAR technique. We also briefly discuss limitations and recent technological advances of this technique with a future perspective.
\end{abstract}

Keywords: InSAR; Crustal Deformation; Case Studies from India

\section{Introduction}

Active microwave remote sensing using Synthetic Aperture Radar (SAR) sensors has become an important tool for wide variety of earth observations. Geophysical applications of SAR interferometry (InSAR) to measure changes in the Earth's surface have been explored since last two decades. InSAR is a method to combine the phases of two different radar images gathered simultaneously or at different times with slightly different looking angles from the satellites. This technique calculates the interference pattern caused by the difference in phase between these images, which can measure the topography or minute changes in the topography of the order of few millimeters along the satellite look direction between two image acquisitions. InSAR has been used to measure surface deformations caused by a variety of sources like earthquakes, landslides, mining etc. The potential of InSAR for seismological application was demonstrated (Massonnet et al., 1993) to map co-seismic deformation caused by the 1992 Landers earthquake. Further, they proved that InSAR could be used as an alternative tool to obtain location, magnitude and type of an earthquake which otherwise could be only possible with seismological observation. Since then, several studies have been attempted for demonstrating the application of InSAR for earthquake deformation studies (Burgmann et al., 2000; Prati et al., 2010 and references therein).

\section{InSAR principle}

A SAR image is a two-dimensional record of both the amplitudes and the phases of the returns from targets within the imaging area. The amplitude is a measure of target reflectivity, whereas the phase encodes changes at the surface. Phase of two SAR images, gathered simultaneously or at different times with slightly different look angles from space can be combined to produce a radar interferogram. The geometry of a typical repeat pass InSAR is provided in Fig. 1. The spatial distance between two orbits of the repeat pass SAR acquisition is called baseline (Fig. 1). Interferometric phase difference between two SAR images could be expressed as (Ferretti et al., 2007)

$$
\begin{aligned}
\Delta \varnothing & =\frac{4 \pi}{\lambda} \frac{B n}{R \sin \theta} h+\frac{4 \pi}{\lambda} \frac{B n}{R \tan \theta} S+\frac{4 \pi}{\lambda} d \\
& +\Delta \varnothing \text { atm }+\Delta \varnothing \lambda
\end{aligned}
$$

where, $\mathrm{h}$ is the topographic height, $\mathrm{s}$ is the relative slant range position, $d$ is the LOS of the relative displacement, $\mathrm{Bn}$ is the perpendicular baseline, $\mathrm{R}$ is the SAR-target distance, $\theta$ is the "off-nadir" angle,

*Author for Correspondence: E-mail: asrajawat@sac.isro.gov.in 
$\Delta \varnothing$ atm is the differential tropospheric delay phase contribution and $\varnothing \gamma$ is the phase noise that depends on temporal and geometric decorrelation of targets.

The first two-phase terms in Eq. (1) represent the phase component due to Flat-earth and surface topography it can be eliminated with the availability of the precise orbital information (baseline, sensortarget distance and off-nadir angle) and precise DEM respectively. The residual phase component, phase, is then proportional to the terrain motion component along the LOS plus atmospheric and decorrelation noise. The decorrelation is typically caused by ground surface changes between image accusations and plays a major role in controlling the accuracy and spatial converges of the InSAR measurements. Atmospheric contribution to the InSAR introduces long wavelength signals and can be modeled by either using atmospheric models or radiometers on-board satellite.

It should be noted that the InSAR measures a change in range along the look direction but is not capable of determining the full three-dimensional displacement vector as in the case of Global Position System (GPS) measurements. On the other hand, InSAR and GPS are fully complementary as GPS provides precise three-dimensional displacements with high temporal sampling intervals, while InSAR provides spatially distributed one dimensional rangechange measurements.

\section{InSAR Studies for Crustal Deformation - Indian Scenario}

InSAR technique have been successfully used to study co-seismic deformation associated with the 1995 Chamoli earthquake (Satyabala and Bilham, 2006) ,Killari earthquake (Satyabala, 2006) and Lushan earthquake (Mathew et al., 2015). The technique was also utilized to map post seismic deformation associated with the 2001 Bhuj earthquake (Chandrasekhar et al., 2009; Saraf et al., 2011; Rastogi et al., 2012, Zia et al., 2014) and low magnitude $(\mathrm{M}=5)$ earthquake in Chamman fault (Furuya and Satyabala, 2008). Bhattacharya et al (2012) estimated interseismic deformation along parts of Himalayan Frontal thrust using InSAR technique. Further, this technique was also used to map surface deformation associated with fluid extraction (Chatterjee et al., 2006), land mining (Chatterjee et al., 2015), landslide motion (Bhattacharya et al., 2015;

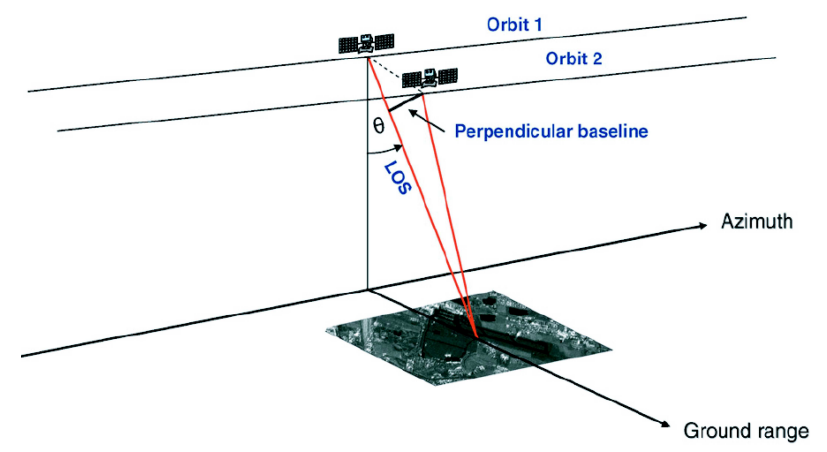

Fig. 1: InSAR acquisition geometry

Bhattacharya and Mukherjee, 2016), geomorphic changes (Majumdar, 2013) and glacier dynamics (Rao, 2011; Saraswat, et al., 2013; Satyabala, 2016). In this article we report and review the recent contributions on earthquake deformation studies from Indian researchers using the InSAR technique. We particularly discuss on the recent InSAR based studies of the 2015 Gorkha, Nepal earthquake (Sreejith, et al., 2016a,b) and the $1992 \mathrm{M}_{\mathrm{w}}=6$ Kohat Plateau earthquake and associated tectonics (Satyabala, et al., 2012).

\section{$M_{w} 7.8$ Gorkha, Nepal, Earthquake}

The catastrophic 25 April 2015, Gorkha, Nepal earthquake of magnitude $\mathrm{M}_{\mathrm{w}} 7.8$ located between Pokhara and Kathmandu $\left(28.147^{\circ} \mathrm{N}\right.$ and $84.708^{\circ} \mathrm{E}$ after U.S. Geological Survey National Earthquake Information Center (NEIC), 2015 and Global Centroid Moment Tensor Catalogue (GCMT), 2015) is one of the largest earthquakes to have struck Nepal since the 1934 Bihar Nepal earthquake of $M_{w} 8.2$ (Sapkota, et al., 2012). The earthquake caused widespread destruction in Nepal and parts of India and China with a total death toll exceeding 9000 and injuring 23000 in an area inhabited by about 8 million people. Moment tensor solutions from tele-seismic data suggest that the Nepal earthquake occurred on a $10-20^{\circ}$ dipping sub-horizontal blind thrust fault at about $15 \mathrm{~km}$ depth with a strike of $290^{\circ}$ from the north (NEIC, 2015). The $M_{w} 7.8$ event was followed by 18 aftershocks with magnitude $>5$ including two events having magnitudes 6.1 and 6.6 on the same day. The largest aftershock occurred on 12 May 2015 about $150 \mathrm{~km}$ east of the main shock (Fig. 2).

Space application Centre, Ahmadabad and Indian Institute of Geomagnetism, Mumbai jointly 


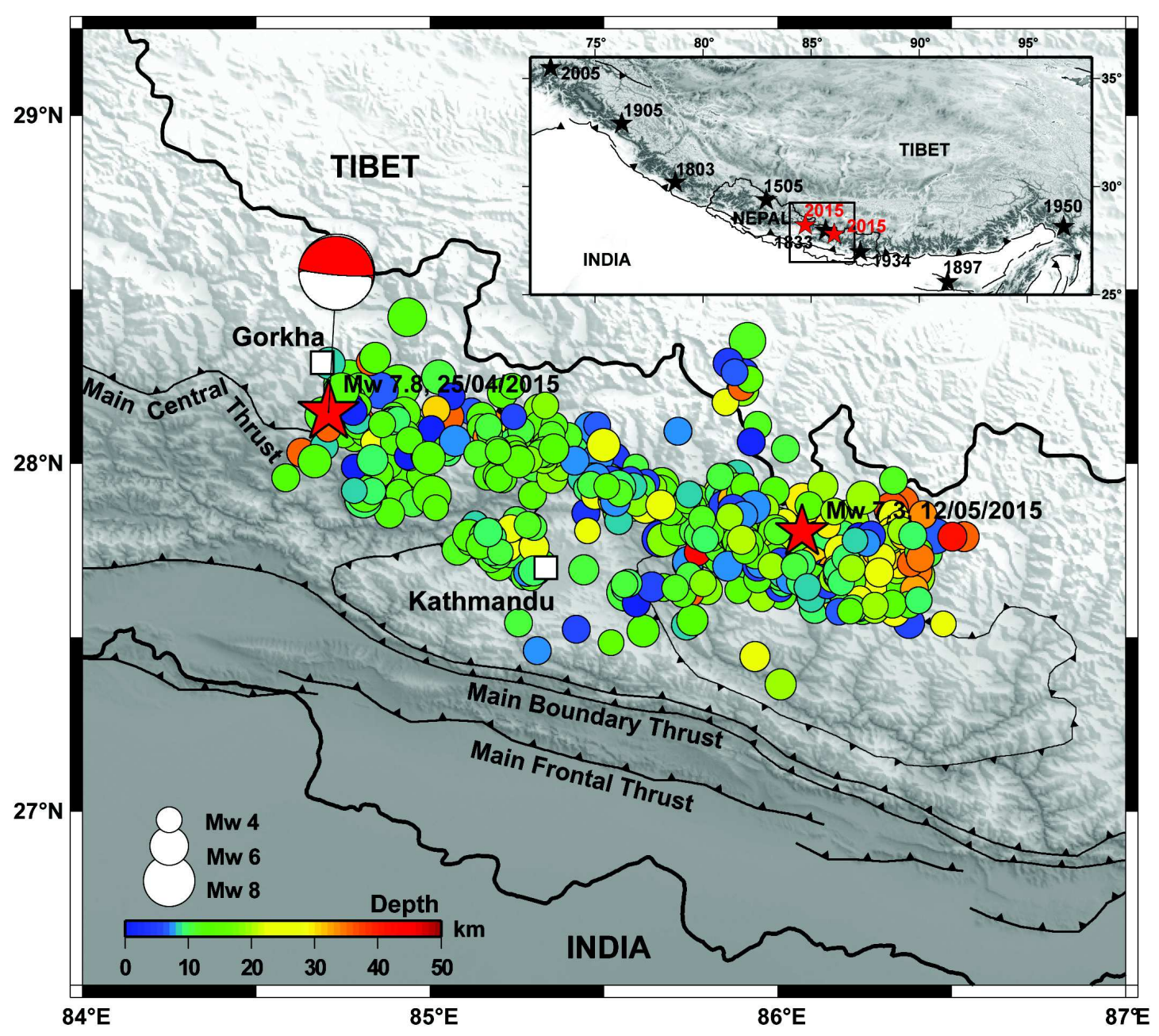

Fig. 2: Map showing the epicenter locations of the 25 April $2015\left(M_{w} 7.8\right)$ Gorkha, earthquake and 12 May $2015\left(M_{w} 7.3\right)$ aftershock (red stars) along with other aftershocks [after Adhikari et al., 2015] in circles. Main Frontal Thrust (MFT), Main Boundary Thrust (MBT) and Main Central Thrust faults (MCT) are shown as black lines. The inset map represents the present study area in rectangle with great and large earthquakes since 1505 in stars

carried out detailed analysis of the co-seismic and early post-seismic deformation of the Gorkha earthquake using InSAR and GPS techniques as a part of the Disaster Management Support Program (DMSP) of the Indian Space Research Organization (ISRO). The results of the studies have provided new constraints on the coseismic and early post-seismic slip on the causative that has important implications in seismic hazard assessment of the Nepal Himalaya.

SAR data from Sentinel-1 satellite and nearfield GPS data from 4 stations (CHLM, KKN4, NAST, and SNDL) of Nepal Geodetic Network were utilized for the coseismic and postseismic investigations of the Gorkha earthquake. The deformation map generated from the coseismic interferogram (Fig. 3A) suggests an upliftment of about $1 \mathrm{~m}$ near Kathmandu and a subsidence of about $0.8 \mathrm{~m}$ towards north along the LOS of the pertinent satellite. The most striking feature of the early postseismic deformation is the reversal in the direction of ground motion with respect to the coseismic deformation (Figs. 3A-3E). Further, it is observed that the postseismic deformation pattern is broader in wavelength and appears to be asymmetric with upliftment towards north of $0.05-0.15 \mathrm{~m}$ (corresponding to the coseismic subsidence) and a subsidence up to $0.07 \mathrm{~m}$ towards south (corresponding to the coseismic upliftment) along the LOS (Figs. 3B3E). The InSAR observations are well supported by the GPS observations. The complementary nature of coseismic and postseismic deformation, the broader 

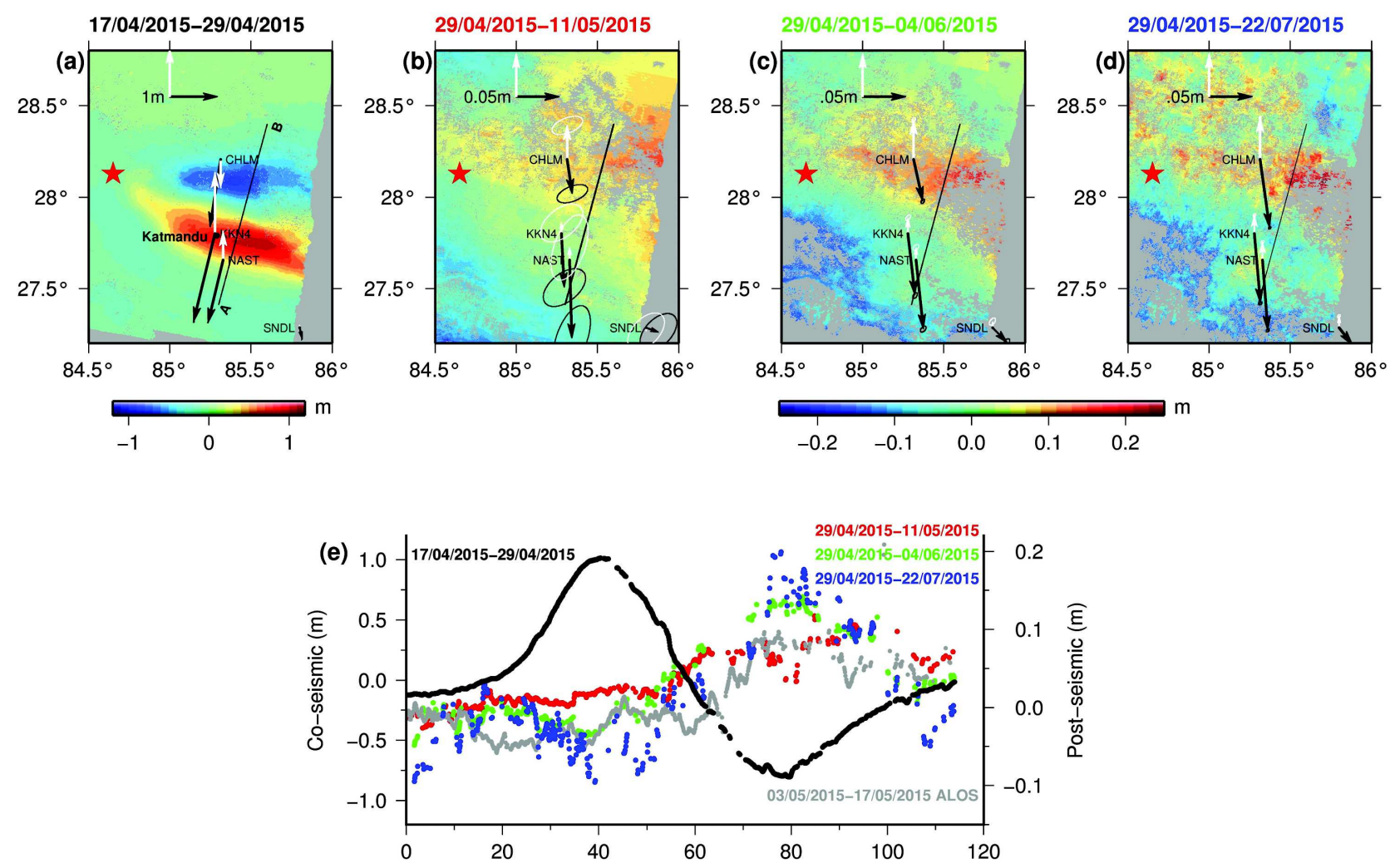

Fig. 3: (A) Coseismic and postseismic deformation maps at different epochs (B, C and D) generated by InSAR analysis (Sreejith et al. 2016). GPS data off-sets corresponding to InSAR epochs in horizontal (black arrow) and vertical (white arrow) directions are shown. Figure $2 e$ indicates the profiles of InSAR data during coseismic (left $Y$ axis) and different postseismic epochs (right $\mathrm{Y}$ axis) as indicated by respective color codes along the section AB. Postseismic deformation along section AB obtained from ALOS interferogram [Lindsey et al., 2015] is also shown (Gray dots)

wavelength of later and the logarithmic fit to the postseismic time series GPS data together indicate afterslip at deeper parts of the causative fault.

The observed deformation pattern of the coseismic deformation was explained by a simple forward model (Sreejith, et al., 2016a) consisting of planar dislocation buried in elastic half-space (Okada, 1985). The model revealed that the overall rupture occurred on a $170 \mathrm{~km}$ long, $60 \mathrm{~km}$ wide fault along the strike $\left(286^{\circ}\right)$ and dipping north $\left(\mathrm{dip}=15^{\circ}\right)$ with large amount of slip $(4.5 \mathrm{~m})$ confined to the center $(95 \times 22$ $\mathrm{km} 2)$ and less slip $(0.25 \mathrm{~m})$ on the surrounding part of the fault plane (Fig. 4). The best fit fault plane has a $\operatorname{dip}=15^{\circ}$ and rake $=98^{\circ}$ with fault centroid at $85.45^{\circ} \mathrm{E}$ and $27.85^{\circ} \mathrm{N}$ located at a depth of $20 \mathrm{~km}$. The slip model obtained from the forward computations is comparable to those obtained from inversion of seismic and geodetic data (Lindsey et al 2015; Wang and Fialko 2015; Galetzka et al., 2015, Grandin et al.,
2015, Avouac et al., 2015). However, the forward model suggests a steeper dip angle $\left(15^{\circ}\right)$ for the causative fault compared to $7^{\circ}-11^{\circ}$ as suggested by the earlier studies. They further noted that the area, depth and dip of the modeled fault plane are fairly consistent and overlap with the location of mid-crustal ramp in MHT with a dip angle $\sim 16^{\circ}$ at a depth of 10$25 \mathrm{~km}$ imaged from the seismic reflection and receiver function stacking studies. The mid-crustal ramp structure is known to have accumulating stress in the inter-seismic period as suggested by micro-seismic and geodetic observations (Pandey et al., 1995; Avouac, 2003). Keeping these observations in view, Sreejith et al., 2016a have suggested that the Gorkha earthquake was possibly caused by the release of inter-seismic strain energy accumulated in the environs of mid-crustal ramp due to plate boundary forces. However, it appears that the hypothesis put forward in this study need to be verified using more sophisticated models. 

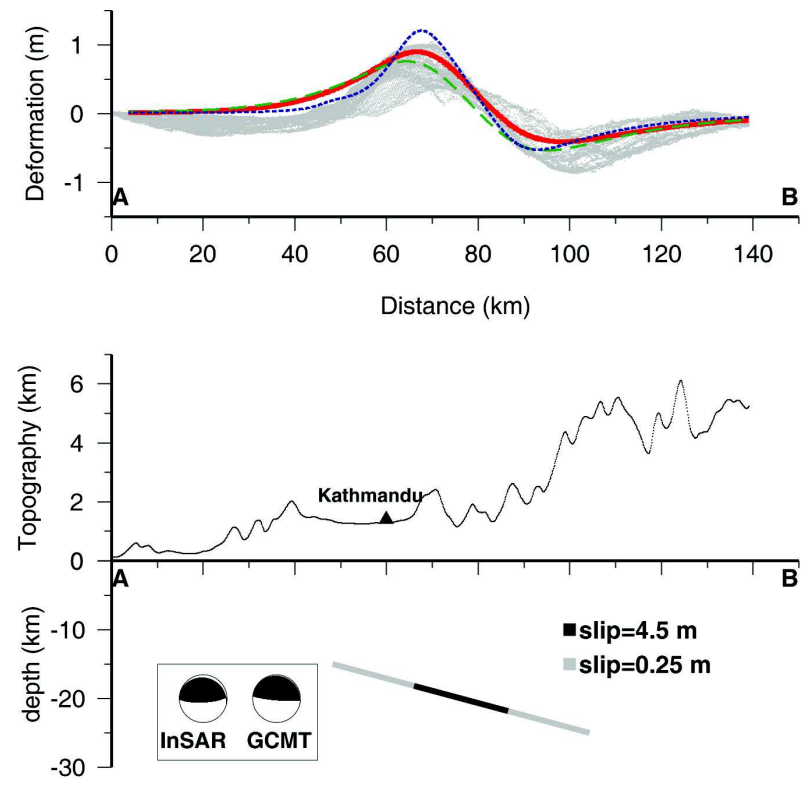

Fig. 4: Forward modeling results of the coseismic deformation caused by the Gorkha earthquake (modified after Sreejith et al., 2016a). LOS deformation along profile $A B( \pm 50 \mathrm{~km}$ either sides $)$ is shown as gray dots. The black line indicates the best fit modeled deformation along the profile AB (dip $=15^{\circ}$ and depth $20 \mathrm{~km}$ ). Deformation models along the profile $\mathrm{AB}$ for $\operatorname{dip}=7^{\circ}$ depth $20 \mathrm{~km}$ (dashed line), dip $15^{\circ}$ and depth=12 km (dotted line) are also shown for comparison. The topography along the profile (middle) and trace of model fault (bottom) are shown. Fault plane solutions obtained from InSAR and that of GCMT are also shown in the bottom panel

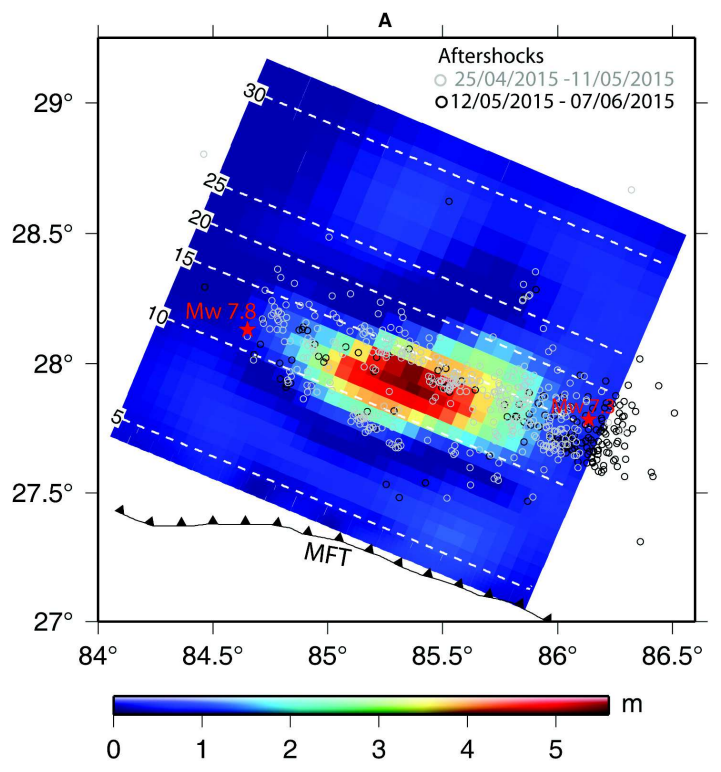

Sreejith, et al., 2016b presented a more realistic fault model for the Gorkha earthquake by joint inversion of InSAR and GPS data (Fig. 5). Their model fault consists of four connected fault segments of variable widths (10-65 km) and dip angles (5-30) representing the complex geometry of MHT as obtained from geophysical studies (Avouac, 2003). The strike of the fault segments considered is $292^{\circ}$ and has variable rakes $\left(90^{\circ}-100^{\circ}\right)$. InSAR and GPS data were jointly inverted to constrained least-squares optimization to solve for the dip-slip and strike-slip components. The coseismic rupture of the Gorkha earthquake is dominated by thrust slip with a maximum value of $5.65 \mathrm{~m}$ along with a minor component from right-lateral slip $(0.6 \mathrm{~m})$. The maximum coseismic slip is about $5.7 \mathrm{~m}$ at a depth of $12 \mathrm{~km}$ (Fig. 5). The coseismic slip model suggests that the nucleation of the earthquake appears to have initiated at the lower bend portion of the flat-mid-crustal ramp transition. The down-dip propagation of the rupture along the steep ramp must have been restricted due to sharp changes in frictional and rheological properties along the ramp, whereas the shallow portion of the MFT remained uninterrupted during the earthquake. Further, they noticed that the lateral extend of the co-seismic rupture is defined by the NE-SW trending Trisouli transfer zone towards west and the rupture area of the $\mathrm{M}_{\mathrm{w}} 8.2,1934$ Nepal-Bihar earthquake towards

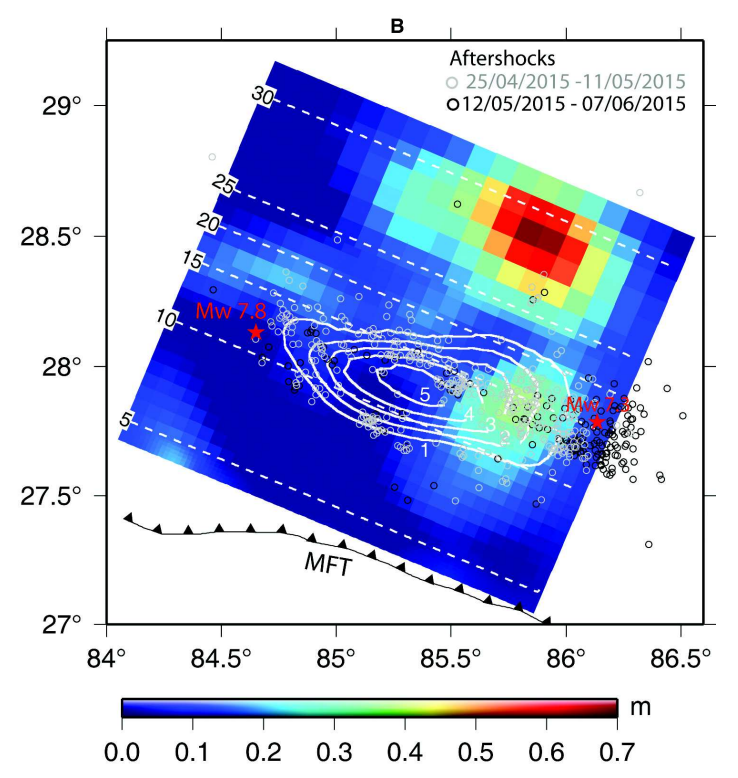

Fig. 5: (A) Coseismic slip model of the 25 April 2015, Gorkha earthquake. Depth to the fault (Dashed white lines) and aftershocks during 25/04/2015-11/05/2015 (Gray dots) and 12/05/2015-07/06/2015 (Black circle) are shown, (B) Postseismic slip model for the 25 April 2015, Gorkha earthquake with co-seismic slip contours (White). (Modified after Sreejith $e t$ al., 2016b) 
east. The four segment fault model presented in this study has provided a better insight to the subsurface slip distribution along the MHT compared to highly simplified fault model presented in previous studies (Wang and Fialko, 2015; Lindsey et al., 2015).

The post-seismic motion has significant contribution from right-lateral slip, particularly along the down-dip patch, where the maximum right-lateral slip is about $0.23 \mathrm{~m}$ and accounts for about half of the dip-slip component (Fig. 5). Comparison of coseismic and postseismic slip models clearly suggests that the coseismic slip occurred along the upper part of the mid-crustal ramp, whereas majority of the postseismic slip (0.1-0.2 m) occurred below the lower edge of the mid-crustal ramp (Fig. 5), where relatively ductile inter-seismic creeping zone exists (Ader et al., 2012). This clearly indicates that the afterslip is predominantly aseismic in nature. It turns out that the segment of MHT where comparatively steep midcrustal ramp interacts with flat fault segments acted as a barrier for stress build-up in central Nepal Himalaya and seems to spawn earthquakes.

The 2015 Gorkha earthquake occurred on a seismic gap between the 1934, 1833 and 1505 events (Fig. 1) and ruptured the deeper portion of the MHT towards east-southeast direction. However, the afterslip model in the present study suggests that the postseismic relaxation is confined to the down-dip and eastern portions of the coseismic asperity. This indicates that a large stress field induced by the thrust motion towards south during the Gorkha earthquake

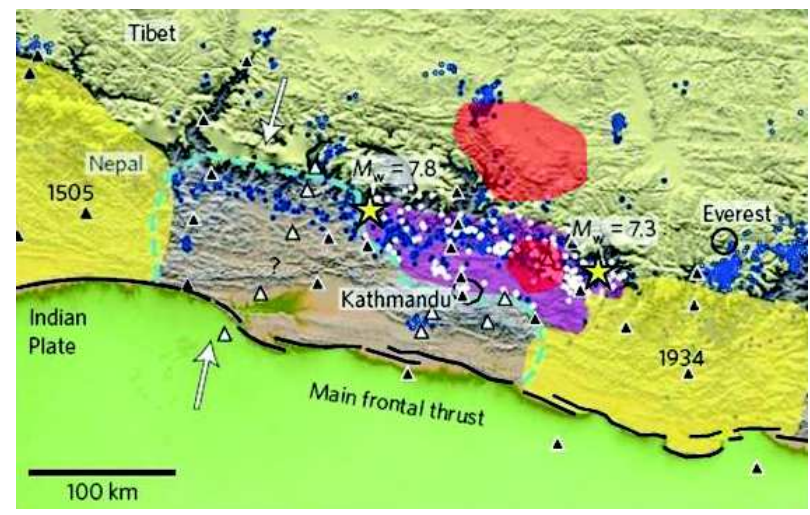

Fig. 6: Map showing rupture area of the Gorkha earthquake (purple), rupture area of 1934 and 1505 earthquakes (yellow) and unruptured portions (blue dashed lines) (After Bilham, 2015). Area of early postseismic slip (Sreejith et al., 2016b) is marked with red shade is not relaxed immediately in the early postseismic period. It increases the risk of another major event as postulated by Bilham (2015) (Fig. 6). However, continued geodetic observations, particularly time series InSAR measurements, are much needed to understand the detailed postseismic behavior of the MHT towards south.

\section{The 1992 Kohat Plateau Earthquake}

On 20 May 1992 an unusual $\mathrm{M}_{\mathrm{w}}=6$ earthquake occurred beneath the Kohat Plateau (Fig. 7) approximately $30 \mathrm{~km}$ north of the Surghar range that bounds its southern edge. The earthquake was larger than any in the historical record and caused damage to nearby cities and loss of life in Kohat. The earthquake is particularly interesting as it occurred on a viscus, sub-horizontal décollement, where aseismic slip dominates over earthquakes in response to stress. The earthquake was captured by InSAR data (Fig. 8) (Satyabala, et al., 2012). Elastic dislocation modeling of the InSAR data suggests that the seismic rupture occurred on a $1^{\circ}$, NNW dipping basal décollement underlying the Kohat Plateau. About $30 \mathrm{~cm}$ slip was occurred on $8 \times 9 \mathrm{~km}^{2}$ a fault plane resulting a moment magnitude of $\mathrm{M}_{\mathrm{w}}=5.9$. The model derived fault parameters are in agreement with that derived form 26 broadband seismic waveform observations.

The seismic and InSAR data thus provide compelling evidence that the décollement slipped

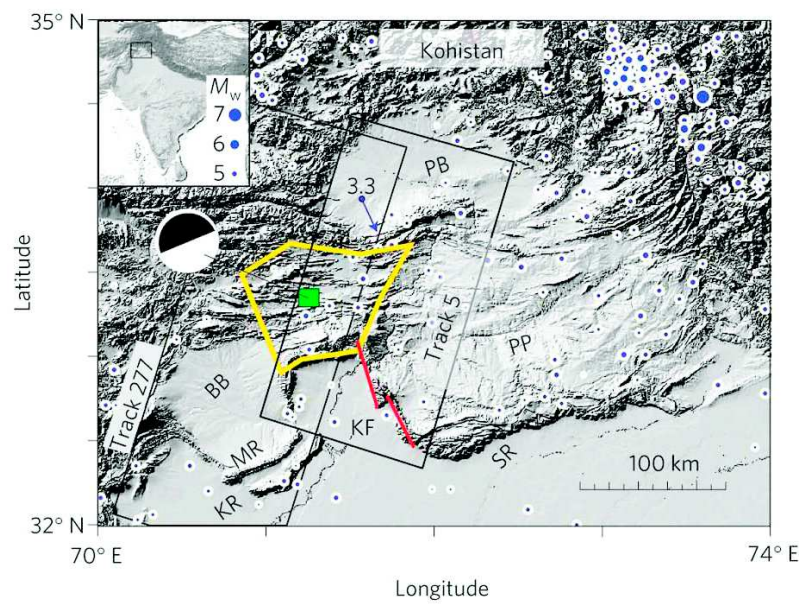

Fig. 7: Topography of Kohat Plateau (yellow polygon) and adjoining regions. Rupture area of 20 May 1992 $M_{w}=6.0$ earthquakes shown as green rectangle in map. InSAR tracks numbered as inclined rectangles. (Figure adopted from Satyabala et al., 2012) 

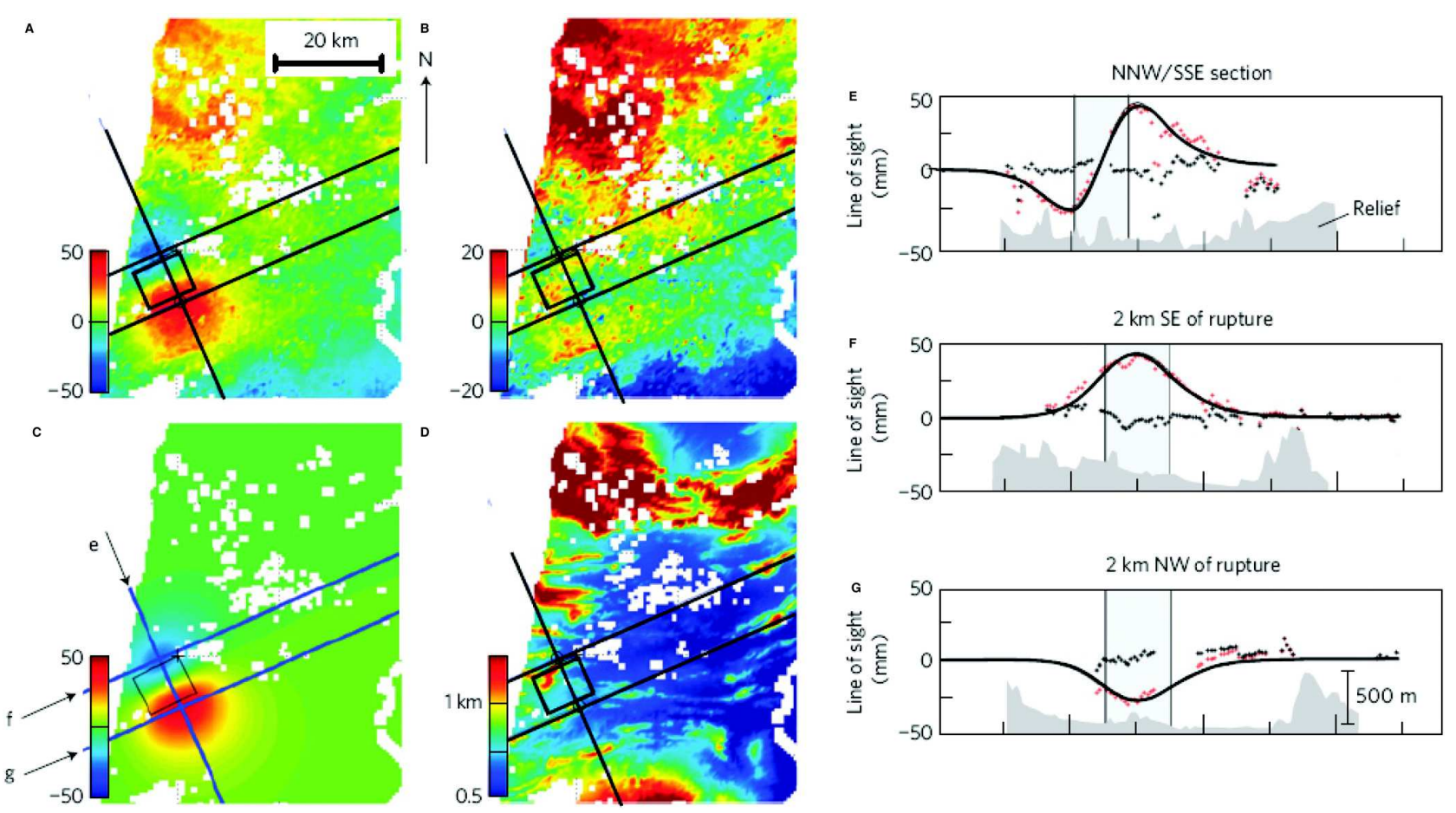

Fig. 8: InSAR data and synthetic model for 1992 earthquake, (A) Coseismic interferogram for 157 days after the Kohat earthquake, (B) Residual after subtracting synthetic model from A, (C) Synthetic interferogram of best-fitting model. Line-of-sight displacement scales in $\mathrm{mm}$ (A-C), (D) Topography for the region and (E-G) Profiles identified in C. Continuous line, model; red and black symbols, coseismic and residual data, respectively. (Figure adopted from Satyabala et al., 2012)

seismically in 1992. The significance of this is that, for horizontal rupture to have occurred, the patch that was stuck must have been loaded by preseismic stresses developed $30 \mathrm{~km}$ north of the frontal thrusts of the Surghar range, and a yet greater distance south of the Kohistan Ranges, where currently $80 \%$ of India's convergence with the Eurasian plate is manifest geodetically (Mohadjer, et al., 2010). Thus the asperity is not located at a transition zone between locked seismic rupture and steady creep, as, for example, occurs in subduction zones or near the base of the high Himalaya. The process is similar to that associated with repeating earthquakes on asperities on creeping faults in central California and elsewhere (Templeton et al., 2008). Creep processes apparently permit the plateau to stream around basal asperities, with strain developing upstream and along their sides.

The cumulative slip of the plateau occurs partly by aseismic slip on a viscous décollement, and partly by seismic slip on one or more asperities where the sediments of the plateau lie directly on the crystalline or sedimentary basement. The décollement beneath the Potwar Plateau is known to consist of Cambrian salt (Yeats et al., 1984), providing weak layer of compliant rheology must exist throughout much of the décollement for aseismic slip to have stressed the 1992 rupture zone. Presumably, the plateau at the location of the 1992 earthquake has been welded to the underlying basement by increased local friction, or has occurred, as in the Potwar Plateau, by the evacuation of viscous materials to the surrounding décollement or into the cores of anticlines developing in association with ramp thrusts. Postseismic interferograms reveal slip of $10 \mathrm{~mm}$ on the décollement in an annulus surrounding the rupture zone (Fig. 9).

The study suggests that the southern Kohat Plateau advances over India partly as a result of creep on a viscous décollement, and partly by stick slip processes on one or more asperities that for prolonged periods are welded to the underlying basement. Thus this part of the plateau does indeed slip with a 


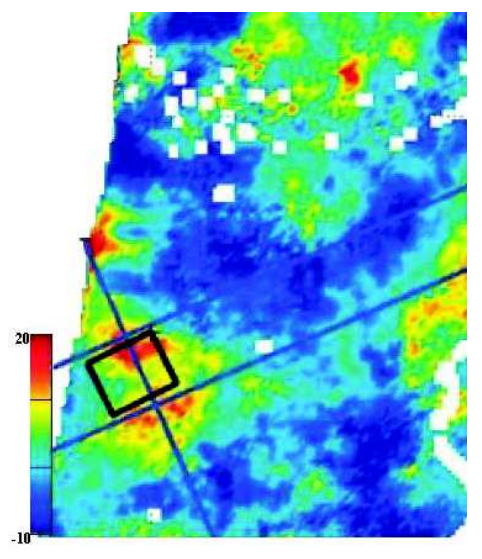

Fig. 9: Afterslip 17-402 d after the 1992 Kohat earthquake from time-series analysis of a post-seismic 30-fold stack spanning 1992-93. (Figure adopted from Satyabala et al., 2012)

caterpillar-like motion. Thus this hybrid seismic and aseismic behaviour represents an evolution of the mode of slip of the plateaux from steady creep towards increasingly widespread seismic rupture.

\section{Future Perspectives}

The InSAR technique has been effectively used to study earthquake induced deformation studies as demonstrated by several case studies. However, lack

\section{References}

Ader T, Avouac J P, Zeng J L, Caen H L, Bollinger L, Galetzka J, Generich J, Thoma M, Chanard K, Sapkota S N, Rajaure S, Shrestha P, Ding L and Flouzat M (2012) Convergence rate across the Nepal Himalaya and interseismic coupling on the Main Himalayan Thrust: Implications for seismic hazard J Geophys Res 117 B04403 doi:10.1029/ 2011JB009071

Avouac J P (2003) Mountain building, erosion and the seismic cycle in the Nepal Himalaya Adv Geophys 46 1-80

Avouac J P, Meng L, Wei S, Wang T and Ampuero J P (2015) Lower edge of locked Main Himalayan Thrust unzipped by the 2015 Gorkha earthquake, Nepal Nature DOI: 10.1038/NGEO2518

Bhattacharya A, Sharma M L and Arora M K (2012) Surface displacement estimation along Himalayan frontal fault using differential SAR interferometry Nat Hazards $\mathbf{6 4}$ $1105-1123$ of seamless data availability, atmospheric distortions and decorrelation effects make the technique more challenging for geophysical applications. Development of regional atmospheric correction models for InSAR, particularly for tropical regions, is important for effective use of the technique. Recent advances in time series InSAR techniques such as Small Baseline Subset Interferometry (SBAS) and Persistent Scatterer Interferometry (PSInSAR) have greatly improved the accuracy of measurement and could be effectively useful in monitoring inter-seismic deformation across active faults and volcanic processes. Further, availability of new high resolution SAR sensors with a short revisiting time such as TerraSAR-X, ALOS-2, Sentinel-1 have provided great opportunity to get precise surface ground motion on a high density of measurement points covering large areas. The joint SAR mission between NASA and ISRO scheduled to be launched in 2020 is expected to provide seamless SAR data in both $\mathrm{L}$ and $\mathrm{S}$ band with a 12-day interferometric orbit that will provide systematic global coverage over all the landmass. These data sets would be particularly useful in understanding the dynamics of the solid earth, cryosphere and ecosystem with unprecedented level of accuracy and coverage.

Bhattacharya A, Mukherjee K, Kuri M, Vöge M, Sharma M L, Arora M K and Bhasin R K (2015) Potential of SAR intensity tracking technique to estimate displacement rate in a landslide prone area in Haridwar Region Nat Hazards 79 2101-2121 doi:10.1007/s11069-015-1949-6

Bhattacharya A and Mukherjee K (2016) Review on InSAR based displacement monitoring of Indian Himalayas: issues, challenges and possible advanced alternatives Geocarto International DOI: 10.1080/10106049.2016.1140820

Bilham R (2015) Raising Kathmandu Nature Geos 8 582-584

Burgmann R, Rosen, P A and Fielding E J (2000) Synthetic Aperture Radar Interferometry to measure Earth's topography and its deformation Annu Rev Earth Planet Sci 28 169-209

Chandrasekhar D V, Burgmann R, Reddy C D, Sunil P S and Schmidt D A (2009) Weak mantle in NW India probed by geodetic measurements following the 2001 Bhuj earthquake Earth Planet Sci Lett 280 229-235 
Chatterjee R S, Fruneau B, Rudant J P, Roy P S, Frison P L, Lakhera R C, Dadhwal V K and Saha R (2006) Subsidence of Kolkata (Calcutta) City, India during the 1990s as observed from space by differential synthetic aperture radar interferometry (D-InSAR) technique Remote Sens Environ 102 176-185

Chatterjee R S, Thapa S, Singh K B, Varunakumar G and Raju E V R (2015) Detecting, Mapping and Monitoring of Land Subsidence in Jharia Coalfield, Jharkhand, India by Spaceborne Differential Interferometric SAR, GPS and Precision Levelling Techniques J Earth Syst Sci 124 13591376 doi:10.1007/s12040-015-0606-5

Furuya M and Satyabala S P (2008) Slow earthquake in Afghanistan detected by InSAR Geophy Res Let doi:10.1029/2007GL033049

Ferretti A, Monti G A, Prati C, Rocca F and Massonnet D (2007) INSAR Principles: Guidelines for SAR Interferometry Processing and Interpretation ESA Publications TM-19

Galetzka, J D, Melgar D, Generich J F, Geg J, Owen S, Lindsey E O, Xu X, Bock Y, Avouac J P, Adhikari L B, Upret B N, Sitaul B P, Bhattrai T N, Moore A, Hudnut K W, Szeliga w, Normandeau J, fend M, Flozat M, Bollinger L, Shrestha P, Kairala B, Gautam U, Bhattarai M, Gupta R, Kandel T, Timsina C, Sapkota S N, Rajaure S and Maharjan N (2015) Slip pulse and resonance of Kathmandu basin during the $2015 \mathrm{M}_{\mathrm{w}} 7.8$ Gorkha earthquake, Nepal imaged with geodesy Science 349 (6252) 1091-1095, DOI: 10.1126/ science.aac6383

Global Centroid Moment Tensor Catalogue (GCMT), (2015), http://www.globalcmt.org

Grandin R, Vallee M, Satriano C, Lacassin R, Klinger Y, Simoes $\mathrm{M}$ and Bollinger L (2015) Rupture process of the $\mathrm{M}_{\mathrm{w}}=$ 7.92015 Gorkha earthquake (Nepal): Insights into Himalayan megathrust segmentation Geophys Res Lett 42 8373-8382 doi:10.1002/2015GL066044

Lindsey E, Natsuaki R, Xu X, Shimada M, Hashimoto H, Melgar D and Sandwell D (2015) Line of Sight Deformation from ALOS-2 Interferometry: $\mathrm{M}_{\mathrm{w}} 7.8$ Gorkha Earthquake and $\mathrm{M}_{\mathrm{w}}$ 7.3 Aftershock Geophys Res Lett 42 6655-6661 doi: 10.1002/2015GL065385

Majumdar T J (2013) Geomorphological characteristics identification from remote sensing along with surface temperature anomaly and SAR interferometry-related studies and their correlation with earthquake occurrences in Gujarat Nat Hazards

Mathew J, Majumdar R and Vinod Kumar K (2015) SAR interferometry and optical remote sensing for analysis of co-seismic deformation, source characteristics and mass wasting pattern of Lushan (China, April 2013) earthquake Int J Appl Earth Obs Geoinf 338-349

Massonnet D, Rossi M, Carmona C, Adragna F, Peltzer G, Feigl $\mathrm{K}$ and Rabaute T (1993) The displacement field of the Landers earthquake mapped by radar interferometry Nature 364 138-142

Mohadjer S, Bendik R, Tschuk A, Kurzikov S, Kostuk A, Saydullaev U, Lodi S, Kakar D m, Wasy A, Khan M A, Molnar P, Bilham R and Zubovich A V, Partitioning of India_Eurasia convergence in the Pamir Hindu Kush from GPS measurements Geophys Res Lett 37 L04305 (2010)

Okada Y (1985) Surface deformation due to shear and tensile faults in a half-space Bull Seismol Soc Am 75 1135-1154

Pandey M, Tankudar R, Avouac J P, Lavé J and Massot J P (1995) Interseismic strain accumulation on the Himalayan crustal ramp (Nepal) Geophys Res Lett 22 751-754

Prati C Ferretti A and Perissin D (2010) Recent advances on surface ground deformation measurement by means of repeated space-borne SAR observations J Geodyn 49 161170

Rao Y S (2011) Synthetic Aperture Radar (SAR) Interferometry for Glacier Movement Studies. In: Singh VP, Singh P, Haritashya UK, editors Encyclopedia of snow, ice and glaciers Netherlands: Springer; p. 1133-1142

Rastogi B K, Choudhury P, Dumka R, Sreejith K M and Majumdar T J (2012) Stress Pulse Migration by Viscoelastic Process for Long - distance Delayed Triggering of shocks in Gujarat, India after the $2001 \mathrm{M}_{\mathrm{w}}$ 7.7 Bhuj Earthquake, in Sharma, S., A. Bunde, D. Baker, and V.P. Dimri (Eds.): Complexity and Extreme Events in Geosciences AGU Geophysical Monograph Series 196 10.1029/2011GM00106

Saraf A K, Das J, Biswas A, Rawat V, Sharma K and Suzat Y (2011) SAR interferometry in post-seismic ground deformation detection related to the 2001 Bhuj earthquake, India Int J Rem Sens 33 1296-1308, DOI: 10.1080/ 01431161.2010 .549855

Saraswat P, Syed T H, Famiglietti J S, Fielding E J, Crippen R Gupta N (2013) Recent changes in the snout position and surface velocity of Gangotri glacier observed from space Int J Rem Sens 3424

Sapkota S N, Bollinger L, Klinger Y, Tapponnier P, Gaudemer Y and Tiwari D (2012) Primary surface ruptures of the great Himalayan earthquakes in 1934 and 1255 Nat Geosci 6 71-76 doi: 10.1038/ngeo1669

Satyabala S P and Bilham R (2006) Surface deformation and subsurface slip of the 28 March $1999 \mathrm{M}_{\mathrm{w}}=6.4$ west Himalayan Chamoli earthquake from InSAR analysis 
Geophys Res Lett 33 L23305 doi: 10.1029/2006GL027422

Satyabala S P (2006) Coseismic ground deformation due to an intraplate earthquake using synthetic aperture radar interferometry: The $\mathrm{M}_{\mathrm{w}} 6.1$ Killari, India, earthquake of 29 September 1993 J Geophys Res 111 B02302 doi: 10.1029/2004JB003434

Satyabala S P, Yang Z and Bilham R (2012) Stick-slip advance of the Kohat Plateau in Pakistan Nat Geosci 5 147-150

Satyabala (2016) Spatiotemporal variations in surface velocity of the Gangotri glacier, Garhwal Himalaya, India: Study using synthetic aperture radar data Remote Sens Environ 181 151-161

Sreejith K M, Sunil P S, Ritesh A, Ramesh D S and Rajawat A S (2016a) Constraints on source parameters of the 25 April $2015, \mathrm{M}_{\mathrm{w}}=7.8$ Gorkha, Nepal earthquake from Synthetic Aperture Radar Interferometry Curr Sci (Accepted)

Sreejith K M, Sunil P S, Ritesh A, Ajish P S, Ramesh D S and Rajawat A S (2016b) Coseismand early postseismic deformation due to the 25 April 2015, $\mathrm{M}_{\mathrm{w}} 7.8$ Gorkha, Nepal earthquake from InSAR and GPS measurements Geophys Res Lett doi: 10.1002/2016GL067907
Templeton D C, Nadeau R M and Burgmann R (2008) Behavior of repeating earthquake sequences in Central California and the implications for subsurface fault creep Bull Seismol Soc Am 98 52-65

U.S. Geological Survey National Earthquake Information Center (NEIC), 2015, http://earthquake.usgs.gov/earthquakes/ search/

Wang K and Y Fialko (2015) Slip model of the $2015 \mathrm{M}_{\mathrm{w}} 7.8$ Gorkha (Nepal) earthquake from inversion of ALOS-2 and GPS data Geophys Res Lett $427452-7458$ doi: 10.1002/2015GL065201

Yeats R S, Khan S H and Akthar M (1984) Late quaternary deformation of the Salt Range of Pakistan Geol Soc Am Bull 95 958-966

Zia M, Sharma K, Saraf A K, Das J, Biswas A, Baral S and Das M (2014) Ground deformational studies using ALOSPALSAR data between 2007 and 2010 of the central Kutch area, Gujarat, India Nat Hazards 71 1379-1388. 